\title{
The Effects of Hypothyroidism on Maternal Health
}

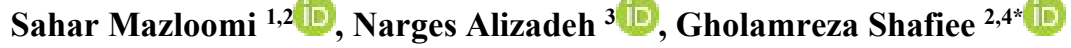 \\ Somayeh Ghorbani 5 (D), Massoume Afsharirad 3 iD \\ 1. Students Research Committee, Hamadan University of Medical Sciences, Hamadan, Iran \\ 2. Dept. of Clinical Biochemistry, School of Medicine, Hamadan University of Medical Sciences, Hamadan, Iran \\ 3. Dept. of Obstetrics and Gynecology, Bijar Imam Hossein Hospital, Kurdistan University of Medical Sciences, Kurdistan, Iran \\ 4. Nutrition Health Research Center, Hamadan University of Medical Sciences, Hamadan, Iran \\ 5. Dept. of Biostatistics, School of Public Health, Hamadan University of Medical Sciences, Hamadan, Iran
}

\begin{tabular}{|c|}
\hline Article Info \\
\hline doi $10.30699 /$ jambs.29.136.279 \\
\hline $\begin{array}{c}\text { Received: 2020/08/24; } \\
\text { Accepted: 2020/03/14; } \\
\text { Published Online: 04 Apr 2021; }\end{array}$ \\
\hline $\begin{array}{l}\text { Use your device to scan and read the } \\
\text { article online }\end{array}$ \\
\hline 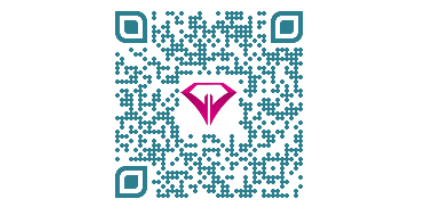 \\
\hline
\end{tabular}

Corresponding Information:

Gholamreza Shafiee,

Dept. of Clinical Biochemistry, School

Medicine, Hamadan University of

Medical Sciences, Hamadan, Iran

E-Mail: g.r_shafiee@yahoo.com

\begin{abstract}
Background \& Objective: Hypothyroidism leads to an increased risk of overweight and obesity. This study examined the effect of weight gain caused by hypothyroidism on maternal health (hypertension, gestational diabetes, and miscarriage) for the first time.
\end{abstract}

Materials \& Methods: This case-control study consisted of 123 pregnant women with clinical hypothyroidism and 242 non-hypothyroid pregnant women as the control group. National guidelines were used to diagnose hypothyroidism in the first trimester. Body mass index (BMI), thyroid-stimulating hormone level, as well as systolic and diastolic blood pressure (BP) were measured. Moreover, fasting blood sugar was assessed during 24-28 weeks of gestation. Data were analyzed by the Chi-square, Student's t-distribution, and logistic regression using the SPSS19 software.

Results: We found a significant relationship between BMI and hypothyroidism in pregnant women $(P<0.001)$. Systolic and diastolic $\mathrm{BP}$ in the case group were higher in women with $\mathrm{BMI} \geq 25(P=0.017$ and $P=0.002)$. Furthermore, diastolic $\mathrm{BP}$ had a significant impact on abortion $(P=0.018)$. The rate of abortion increases by 1.042 with $1 \mathrm{mmHg}$ elevation in diastolic BP in pregnant women if the variables maternal age, hypothyroidism, and overweight are constant.

Conclusion: According to the results of the present study, weight gain in women with hypothyroidism can affect the risk of high diastolic BP and abortion.

Keywords: Abortion, Hypertension, Hypothyroidism, Obesity, Overweight

(C) (i) (1) Copyright $(C)$ 2021, This is an original open-access article distributed under the terms of the Creative Commons Attribution-noncommercial 4.0 International License which permits
copy and redistribution of the material just in noncommercial usages with proper citation.

\section{Introduction}

The prevalence of hypothyroidism has been reported to be $2.5 \%-7.5 \%$ in several studies (1). Since most thyroid disorders are autoimmune, the incidence rate in women is 10 times higher than in men (2). Thyroid disorders are common in young females and pregnancy affects the physiology and function of the thyroid in mothers (3). Thyroid function in pregnancy may change due to different causes, such as iodine deficiency, human chorionic gonadotropin (hCG), and estrogen (4). The thyroid gland in a fetus is not active before the $20^{\text {th }}$ week of pregnancy. Therefore, the brain in a fetus is specifically dependent on the mother in terms of thyroid hormones.

Any type of hypothyroidism (i.e., primary and subclinical) with any causes increases the risk of abortion, preeclampsia, low birth weight, and premature birth along with reducing the intelligence quotient (IQ) of a child (5). Thyroid disorders cause mother and fetus injuries. Women with thyroid disorders experience abnormal hemorrhage, recurrent miscarriage, ovarian failure, gestational diabetes mellitus (GDM), preterm labor, admission at NICU, and neonatal death (6).

Hypothyroidism in a pregnant mother results in intrauterine growth retardation, developmental neuropsychiatric disorders of the fetus, low birth weight, respiratory distress syndrome, spontaneous abortion, fetal death, infertility prevalence, premature birth, placental abruption, and preeclampsia. Moreover, subclinical hypothyroidism is a risk factor for abortion before the $20^{\text {th }}$ week of pregnancy (7). Subclinical hypothyroidism is usualy associated with adverse outcomes. Untreated subclinical hypothyroidism in pregnant women is associated with higher risk of placental abruption, pregnancy loss, neonatal death and premature rupture of membranes (8).

A high body mass index (BMI) may be one of the signs of hypothyroidism. Obesity is a common problem in 
pregnancy that affects mother and fetus causing short- and long-term complications for mothers, such as increasing the risk of GDM and preeclampsia (9). In addition, the risk of spontaneous abortion is 1.67 times higher among overweight and obese women (10). Some studies found that the placentas of obese women have higher lipid content (11).

Pre-pregnancy overweight can augment cesarean delivery and the rate of preeclampsia increases by $0.1 \%$ in these women (12). Several investigations demonstrated that the rate of low birth weight and preeclampsia are higher in obese adolescent women $(13,14)$. Obesity is considered a risk factor for gestational hypertension (15).

Hypertension is uncommon during pregnancy and the lack of treatment for hypertension is a risk factor for both mother and child. High BMI during pregnancy has an incremental influence on systolic and diastolic blood pressure (BP) (16). Recent studies have shown an increase in diastolic BP in women with preeclampsia $(17,18)$. For every $10 \mathrm{~mm} \mathrm{Hg}$ diastolic BP increase, the risk of abortion is $18 \%$ higher (19).

Considering the prevalence of obesity and the fact that obesity affects both mother and child health, this study investigated the effect of weight gain resulting from gestational hypothyroidism on maternal health complications, including hypertension, GDM, and abortion.

\section{Materials and Methods}

\section{Subjects}

In order to monitor hypothyroidism during pregnancy, all pregnant women refer to the gynecology clinic in the first trimester of pregnancy and are included in the national hypothyroidism monitoring plan during the first trimester. According to our national guidelines, the normal range of thyroid-stimulating hormone (TSH) levels is $0.2-3.99 \mu \mathrm{U} / \mathrm{mL}$ in the first pregnancy trimester.

A total of 365 pregnant women were included in this case-control study, of which 123 individuals with the symptoms of hypothyroidism were considered as the case group and 242 healthy pregnant women were considered as the control group. The participants in the two groups were similar in terms of maternal and gestational age. All the patients were outpatients at the Obstetrics Clinic of Imam Hossein Hospital, Bijar affiliated to the Kurdistan University of medical sciences, Iran in 2017.

Approval was obtained from the Ethics Committee of Hamadan University of Medical Sciences, Iran with the code of IR.UMSHA.REC.1397.265.

\section{Measurements}

\section{BP and BMI}

The BP of participants was measured at a sitting position by Welch Allyn digital blood pressure device. Bodyweight was measured with an accuracy of $0.1 \mathrm{~kg}$ applying a balanced-beam scale. Height was measured with a stadiometer with an accuracy of $0.5 \mathrm{~cm}$. The BMI of individuals was calculated based on the weight/(height $)^{2}$ formula

\section{TSH}

Blood samples were collected at 8-9 a.m. after at least $12 \mathrm{~h}$ fasting. The TSH level was examined by enzymelinked fluorescent assay (ELFA) using the VIDAS instrument. The detection limit of the ELFA method is $0.05 \mu \mathrm{U} / \mathrm{mL}$ for $\mathrm{TSH}$.

\section{Proteinuria}

According to the American College of Obstetricians and Gynecologists (ACOG) guideline, preeclampsia is proteinuria of $300 \mathrm{mg}$ and/or +1 on urine test strips after 20 weeks of pregnancy in combination with systolic blood pressure $(\mathrm{SBP}) \geq 140 \mathrm{mmHg}$ and a diastolic $\mathrm{BP} \geq 90$ $\mathrm{mmHg}$.

\section{Blood Glucose}

Blood glucose level was measured during weeks 24-28 of gestation to monitor GDM. The blood glucose level was analyzed by an enzymatic method using a commercial kit (Pars Azmun, Iran) according to the instructions of the manufacturer.

\section{Statistical Analysis}

The results of descriptive statistics are presented as mean \pm SD. Data were analyzed by the Chi-square, Student's t-distribution, and logistic regression using the SPSS software version 19 (IBM, Chicago, Ill., USA). The significance level was considered $\mathrm{P}$-value $<0.05$.

\section{Results}

The mean age of studied individuals was 30 years old with the youngest and oldest being 14 and 45 years old, respectively. The study groups were matched for maternal age $(P=0.688)$. Moreover, the groups were similar in terms of gestational age as all mothers were in the first trimester.

Table 1 represents the mean of the examined parameters in the two groups calculated by the MannWhitney U test. According to the outputs of the Chisquare test, BMI and hypothyroidism were significantly related in pregnant women $(P<0.001)$. The prevalence of hypothyroidism in overweight women $(\mathrm{BMI} \geq 25)$ was 3.046 times higher than the individuals in the control group.

Regardless of the grouping variable, there was no significant difference between the systolic and diastolic BPs of overweight participants $(B M I \geq 25)$ and individuals with normal weight $(\mathrm{BMI}<25)$. However, different results were observed for the mean BPs in both groups based on BMI (Table 2).

Furthermore, the mean abortion in both groups was evaluated based on BMI (Table 3). Separate univariate regression analyses showed that diastolic BP affected abortion significantly $(P=0.018)$, while SBP had no significant influence on abortion $(P=0.069)$. Neither 
hypothyroid variables $(P=0.530)$ nor BMI $(P=0.553)$ significantly affected abortion.

Finally, multiple logistic regression was used to determine the simultaneous effects of maternal age, hypothyroidism, overweight, and BP on the abortion rate. According to the results of this analysis presented in Table $\underline{4}$, only maternal age and diastolic BP influenced the rate of abortion. Hypothyroid and BMI variables were not related to abortion.
If some variables, namely maternal age, hypothyroidism, and overweight are constant, abortion increases by 1.042 for each $1 \mathrm{mmHg}$ augmentation in the diastolic BP of a pregnant mother. Moreover, if some variables, including BP, hypothyroidism, and overweight are constant, the rate of abortion elevates by 1.06 for each unit of raise in the age of the pregnant mother. In other words, both the age and BP of a pregnant mother have a positive effect on the abortion rate.

Table 1. Mean of the parameters studied in both groups.

\begin{tabular}{|c|c|c|c|}
\hline Variable & $\begin{array}{l}\text { Control group } \\
(\mathrm{n}=\mathbf{2 4 2})\end{array}$ & $\begin{array}{l}\text { Hypothyroidism group } \\
\qquad(\mathrm{n}=123)\end{array}$ & P-value \\
\hline TSH $^{\mathbf{a}}$ & $2.2166 \pm 5.6813$ & $4.2849 \pm 3.8964$ & $<0.001$ \\
\hline $\mathbf{B M I}^{\mathbf{b}}$ & $24.6736 \pm 5.3769$ & $27.1236 \pm 4.5655$ & $<0.001$ \\
\hline Age & $30.3182 \pm 6.8063$ & $30.0244 \pm 6.2047$ & 0.688 \\
\hline Systolic BPc & $103.1777 \pm 8.7285$ & $106.0976 \pm 11.0427$ & 0.011 \\
\hline Diastolic BP & $64.9504 \pm 6.7870$ & $66.6829 \pm 6.2716$ & 0.019 \\
\hline Abortion & $0.2149 \pm 0.4115$ & $0.2439 \pm 0.431$ & 0.531 \\
\hline FBS $^{d}$ & $86.9835 \pm 10.5112$ & $89.0569 \pm 9.0193$ & 0.063 \\
\hline
\end{tabular}

a, thyroid stimulating hormone; b, body mass index; c, blood pressure; $d$, fasting blood sugar

Table 2. Mean systolic and diastolic blood pressure in both groups according to BMI.

\begin{tabular}{ccccc} 
Variable & Hypothyroidism & $\begin{array}{c}\text { BMI } \geq \mathbf{2 5} \\
(\mathbf{M e a n} \pm \text { SD) }\end{array}$ & $\begin{array}{c}\text { BMI<25 } \\
(\text { Mean } \pm \text { SD })\end{array}$ & $\begin{array}{c}\text { P-value } \\
\text { Systolic BPa }\end{array}$ \\
& Control & $110.000 \pm 11.792$ & $104.667 \pm 10.461$ & 0.017 \\
& Hypothyroidism & $69.576 \pm 6.175$ & $103.278 \pm 8.867$ & 0.608 \\
Diastolic BP & Control & $66.615 \pm 6.682$ & $65.622 \pm 5.997$ & 0.002 \\
& & & $64.759 \pm 6.793$ & 0.189 \\
\hline
\end{tabular}

a: blood pressure

Table 3. Mean abortion in both groups according to BMI.

\begin{tabular}{ccccc} 
Variable & & $\begin{array}{c}\text { BMI } \geq 25 \\
(\mathbf{M e a n} \pm \text { SD })\end{array}$ & $\begin{array}{c}\text { BMI }<25 \\
(\mathbf{M e a n} \pm \text { SD) }\end{array}$ & P-value \\
\multirow{2}{*}{ Abortion } & Hypothyroidism & $0.259 \pm 0.441$ & $0.217 \pm 0.417$ & 0.600 \\
& Control & $0.239 \pm 0.428$ & $0.200 \pm 0.401$ & 0.474 \\
\hline
\end{tabular}

Table 4. Logistic regression analyses of diastolic BP and other confounding variables to predict abortion.

\begin{tabular}{cccccc}
$\begin{array}{c}\text { Dependent } \\
\text { variable }\end{array}$ & $\begin{array}{c}\text { independent } \\
\text { variable }\end{array}$ & B \pm S.E & Wald statistic & OR & P-value \\
& Diastolic BP & $0.041 \pm 0.020$ & 4.307 & 1.042 & 0.038 \\
\multirow{2}{*}{ Abortion } & Age & $0.058 \pm 0.020$ & 7.996 & 1.060 & 0.005 \\
& Group & $0.113 \pm 0.281$ & 0.162 & 1.120 & 0.688 \\
& BMI $^{\mathrm{b}}$ & $0.004 \pm 0.032$ & 0.017 & 1.004 & 0.898 \\
\hline
\end{tabular}

a, blood pressure; b, body mass index

\section{Discussion}


Thyroid disease is the second most common endocrine disorder after diabetes in women of reproductive age. There are similarities between the symptoms of thyroid disease and pregnancy. Therefore, problematic disease diagnosis causes a delay in a definitive diagnosis, which can be followed by irrecoverable effects for both mother and fetus (19).

The high prevalence of overweight and obesity following hypothyroidism, specifically during pregnancy, can cause problems. Obesity can lead to BP disorders and preeclampsia. The findings of the present study differed from the results reported by previous studies. However, our results indicated that weight gain in women with hypothyroidism can influence the increase in diastolic BP and abortion.

Lotfalizade et al. observed subclinical hypothyroidism in 212 out of 1,000 pregnant women in the first trimester in Mashhad, Iran. The researchers divided pregnant women with subclinical hypothyroidism into two treated and untreated groups. Their results indicated that the rates of placental abruption and premature birth were significantly higher in the untreated group. However, the two groups had no significant difference in terms of preeclampsia prevalence. It is believed that SBP $\geq 140 \mathrm{mmHg}$ and diastolic $\mathrm{BP} \geq 90 \mathrm{mmHg}$ are the signs of preeclampsia. Consequently, the present study did not consider the hypothyroid factor.

The results showed that the rate of abortion augmented by 1.042 for each $1 \mathrm{mmHg}$ increase in diastolic BP. Moreover, abortion was elevated by 1.06 for each unit of raise in the age of mothers. Furthermore, we found a significant relationship between BMI and hypothyroidism in pregnant women (20).

Our study revealed a significant relationship between hypothyroidism and BMI in women as hypothyroidism had an occurrence of 3.046 times higher in obese participants than the normal weight ones. These results were consistent with the findings of Cheng et al. in China. They found TSH to be significantly related to FT4 levels and weight gain in obese pregnant women (13). Mosso et al. demonstrated that higher BMI in the first trimester was accompanied by decreased thyroid function in women in Chile. According to the results of the present study and the mentioned researches, high BMI may be a sign of hypothyroidism (19).

Another study by Pop et al. showed no relationship between hypothyroidism and BMI in the $12^{\text {th }}$ week of pregnancy. Their findings were not in line with our results because we examined pregnant women in the first trimester. In the current study, the age range was higher than the study conducted by Pop (21). Yang et al. indicated that subclinical hypothyroidism enhanced recurrent miscarriage in China. Although the present study did not find a direct effect for hypothyroidism on abortion, significant relationships were observed between hypothyroidism and BMI, as well as diastolic and systolic BPs. Therefore, hypothyroidism is expected to indirectly affect abortion (22).

Previous studies have proven that high serum TSH level is correlated with spontaneous abortion, hypertensive disorders, and preterm birth. In the present study, in line with previous studies, hypothyroidism increased BP and possibly the risk of miscarriage during pregnancy $(23,24)$.

Moreover, high levels of TSH were reported in obese non-pregnant women. Diverse mechanisms are involved in the impact of obesity on TSH augmentation by activating endocrine organs. In addition, it is increased due to the release of leptin, cytokine, and other inflammatory factors by adipose tissue. Our study also showed a clear relationship between overweight and high levels of TSH (25). Medici et al. demonstrated higher BP in mothers with hyperthyroidism in the Netherlands. However, no relationship was found between hypothyroidism and hypertension. Nevertheless, our results showed higher diastolic BP in hypothyroidism women, which contradicted the results reported by Medici et al (26).

The present study findings revealed that hypothyroidism increased the prevalence of high diastolic BP by 0.04 . Moreover, this study indicated that hypothyroidism in obese people significantly increased BP. A variety of factors, such as stress, consumption of supplements, diet, racial differences, and lifestyle affect BP and can justify the differences in results (27-29).

The results of this study were congruent with the data presented by Ashoor et al. in Spain. In this study, the prevalences of hypertension and preeclampsia were five times higher in women with high TSH, compared to individuals with normal TSH. Although our study did not find a significant relationship between hypothyroidism and preeclampsia, elevated diastolic $\mathrm{BP}$ was found in this group. We observed that an increase in the diastolic BP of pregnant mothers augmented the abortion rate by 1.042 (30).

A meta-analysis conducted by Metwally et al. in England indicated a higher risk of spontaneous abortion in obese women (10). However, the present study did not reveal any significant relationship between obesity, weight gain, and abortion.

A direct relationship was found between diastolic BP and abortion in our investigation as overweight caused a rise in systolic and diastolic BPs in women with hypothyroidism. It could be concluded that hypothyroidism, which results in overweight, obesity, and hypertension can affect abortion. The controversy between our results and the findings of Metwally et al. could be attributed to the difference in sample size and factors that affect abortion. It should be noted that our study just investigated abortion, not a recurrent miscarriage (10). 
In our study, in line with the study of Azizi et al. in Iran, the results showed that hypothyroidism in pregnancy is associated with gestational hypertension and abortion (31). The findings of a retrospective study in Saudi Arabia showed the adverse effects of hypothyroidism on the fetus and mother. Given that, the relationship between maternal hypothyroidism and infant death has been reported, the results of the mentioned study could be consistent with our findings as both have reported an increased risk of miscarriage in hypothyroid pregnant women with high diastolic BP (6).

A study by Sahila et al. in India demonstrated that TSH level and obesity were significantly higher in pregnant women with hypertension in the third trimester of pregnancy, compared to the control group. Although our results were for the first trimester of pregnant women with hypothyroidism, these data are in line with the correlation reported between hypothyroidism, hypertension, and overweight in pregnant women (32).

In our previous studies on preeclampsia, we indicated that diastolic BP augmented in preeclampsia cases. These results may be the reason for increased preeclampsia in these women due to the elevation in diastolic BP in pregnant women with hypothyroidism. However, there was no difference in the amount of excreted protein $(17,18)$.

\section{Conclusion}

According to the results and the impact of hypothyroidism on BMI, it may be concluded that overweight in women with hypothyroidism can affect abortion by causing high diastolic BP. Therefore, it is expected that the risk of hypothyroidism reduces in these women through a weight control program leading to the ensured health of both mother and fetus.

\section{Acknowledgments}

This study was supported by Students Research Center of Hamadan University of Medical Sciences and Kurdistan University of Medical Sciences. All authors have nothing to declare.

\section{Funding}

This work was supported by Students Research Center of Hamadan University of Medical Sciences [grant NO. 9705022569].

\section{Conflict of Interest}

Authors declared that they have no conflicts of interest.

\section{References}

1. Biglievi EG, Salton PE. Pregnancy and primay hypothyroidism. J Clin Endocrinol Metab. 2003; 27(1): 1628-30.

2. MacFarlane I. Thyroid disease. Pharmaceut J. 2019; 265(7109):240-44.

3. Alessandro P.D, Giampiero C, Pier LC, Salvatore D, Giuseppe Delitala. Thyroid function and thyroid disorders during pregnancy: a review and care pathway. Arch Gynecol Obstet. 2019; 299:327-38. [DOI: 10.1007/s00404-018-5018-8]

4. Zhang Y, Wang H, Pan X, Teng W, Zhongyan Shan. Patients with subclinical hypothyroidism before 20 weeks of pregnancy have a higher risk of miscarriage: A systematic review and metaanalysis. 2017; PLoSONE 12(4):e0175708. [DOI:10.1371/journal.pone.0175708]

5. Canningham F, Leveno K, Bloom S, Hauth J, Gilstrap L, Wenstrom R. Williams obstetics, 22nd ed, Mc Graw-Hill, 2005; pp1340-8.

6. Fallatah A M, Hasanain A, Babatin H, Nassibi KH M, Thigah S ,Abduljabbar H S. Pregnancy outcomes among obese pregnant women with hypothyroidism: medical record review of a single tertiary center in Saudi Arabia. Cureus. 2020; 12(2): e6938 [DOI: 10.7759/cureus.6938]

7. Sun Y Lee. Subclinical hypothyroidism in pregnancy may have long-term effects on metabolic parameters. J Clin Endocrinol Metab.2020; 105(7):e2628-29. [DOI:10.1210/clinem/dgaa198]

8. Maraka S, Mwangi R, G McCoy R, et al. Thyroid hormone treatment among pregnant women with subclinical hypothyroidism: US national assessment. BMJ. 2017;356:i6865. [DOI:10.1136/bmj.i6865]

9. Patrick M Catalano, Kartik Shankar. Obesity and pregnancy: mechanisms of short term and long term adverse consequences for mother and childpregnancy and postpartum. BMJ. 2017;356: 1-16.

10. Metwally M, Ong KJ, Ledger WL, Li TC. Does high body mass index increase the risk of miscarriage after spontaneous and assisted conception? A meta-analysis of the evidence. Fertil Steril. 2008;356:714-26. 
11. Calabuig-Navarro V, Puchowicz M, Glazebrook $P$, et al. Effect of $\omega-3$ supplementation on placental lipid metabolism in overweight and obese women. Am J Clin Nutr. 2016;356:106472.

12. Hatice Kansu-Celik, Burcu Kisa Karakaya, Ali Irfan Guzel, Yasemin Tasci, Salim Erkaya. To evaluate the effect of pre-pregnancy body mass index on maternal and perinatal outcomes among adolescent pregnant women. J MaternFetal Neonatal Med. 2017; 30(13):1574-1578. [DOI:10.1080/14767058.2016.1214122]

13. Cheng $\mathrm{H}, \mathrm{Li} \mathrm{C}$, Mao J, et al. High body mass index is an indicator of maternal hypothyroidism,hypothyroxinemia, and thyroid-peroxidase antibody positivity during early pregnancy. BioMed Res Int. 2015;2015:351831. [DOI: 10.1155/2015/351831]

14. Haeri S, Guichard I, Baker AM, Saddlemire S, Boggess KA. The effect of teenage maternal obesity on perinatal outcomes. Obstet Gynecol. 2009;113:300-4.

\section{[DOI:10.1097/AOG.0b013e3181945b8a]}

15. Mission JF, Marshall NE, Caughey AB Pregnancy risks associated with obesity Obstet Gynecol Clin North Am. 2015;42:335-53.

16. Nobles C, Mendola P, Mumford S,et al. Preconception blood pressure levels and reproductive outcomes in a prospective cohort of women attempting pregnancy. Hypertension. 2018; 71(5): 904-910. [DOI:10.1161/HYPERTENSIONAHA.117.10 705]

17. Mazloomi S, Alimohammadi S, Khodadadi I, Ghiasvand T, Shafiee G. Evaluation of methylene tetrahydrofolate reductase (MTHFR) activity and the levels of homocysteine and malondialdehyde (MDA) in the serum of women with preeclampsia. Clin Exp Hypertens. 2020 ;42(7):590-94. [DOI: $10.1080 / 10641963.2020 .1739700]$

18. Mazloomi S, Khodadadi I, Alimohammadi S, Shafiee G. Correlation of thioredoxin reductase (TrxR) and nitric oxide synthase (NOS) activities with serum trace elements in preeclampsia. Clin Exp Hypertens. 2020;1-5. [DOI: 10.1080/10641963.2020.1817476]

19. Mosso L, Martínez A, Paulina Rojas M, et al. Early pregnancy thyroid hormone reference ranges in Chilean women: The influence of body mass index. Clin Endocrinol (Oxf). 2016 ; 85(6): 942-948. [DOI:10.1111/cen.13127]

20. Lotfalizadeh M, Ghomian N, Mohammad Nezhad M. Prevalence and complications of hypothyroidism in pregnancy. Iran J Obstet, Gynecol Infertil. 2017;20 (8):1-5.

21. Pop V, Biondi B, Hennie A, Simone W, Kuppens M, Vader H. Maternal thyroid parameters, body mass index and subsequent weight gain during pregnancy in healthy euthyroid women. Clin Endocrinol. 2013;79:577-83. [DOI:10.1111/cen.12177]

22. YangJ, GuoH, DingS, TaoB, ZhangX. Effect of the treatment acceptance on the perinatal outcomes in women with subclinicalhypothyroidism ,positivethyroid gland peroxidase antibody in earlypregnancy. ZhonghuaFuChanKeZaZhi 2015;50:652-657.

23. Luisi S, Giorgi M, Riggi S, Messina G, Maria Severi F. Neonatal outcome in pregnancy hypotiroidee women. Gynecol Endocrinol. 2020;36(9):772-75 [DOI: 10.1080/09513590.2019.1706083]

24. Alexander EK, Pearce EN, Brent GA, et al. Guidelines of thyroid American association for the diagnosis and management of thyroid disease during pregnancy and the postpartum. Thyroid. 2017;27(3): 315-89 [DOI: 10.1089/thy.2016.0457]

25. de Moura Souza A, Sichieri R. Association between serum TSH concentration within the normal range and adiposity. Europ J Endocrinol. 2011; 165(1):11-5. [DOI:10.1530/E]E-110261]

26. Medici M1, Korevaar TI, SchalekampTimmermans S, et al. Maternal early-pregnancy thyroid function is associated with subsequent hypertensive disorders of pregnancy: the generation R study. J Clin Endocrinol Metab. 2014;99(12):E2591-8. [DOI:10.1210/jc.20141505]

27. Ormesher L, Myers J, Chmiel C, et al. Effects of dietary nitrate supplementation, from beetroot juice, on blood pressure in hypertensive pregnant women: A randomised, double-blind, placebo-controlled feasibility trial. Nitric Oxide. 2018;

$37-44$. [DOI: 10.1016/.niox.2018.08.004]

28. Yusuf H, Subih H, Obeidat B, Sharkas G. Associations of macro and micronutrients and antioxidants intakes with preeclampsia: A casecontrol study in Jordanian pregnant women. Nutr, Metab \& Cardiovas Dis. 2019; 29 (5):45866. [DOI: 10.1016/j.numecd.2019.01.008]

29. Bullarbo $\mathrm{M}$, Mattson H, Karin Broman A, Ödman N, Nielsen T. Magnesium supplementation and blood pressure in pregnancy: A double-blind randomized multicenter study. J Pregnancy. 2018; 
2018:4843159.

[DOI: 10.1155/2018/4843159]

30. Ashoor G, Maiz N, Rotas M, Kametas N, Nicolaides K. Maternal thyroid function at 11 to 13 weeks of gestation and subsequent development of preeclampsia. Prenat Diagn. 2010;30: 1032-38. [DOI:10.1002/pd.2566]

31. Azizi F, Amouzegar A, Mehran L, et al. Screening and management of hypothyroidism in pregnancy: results of an Asian survey. Endocr J. 2014;61(7):697-704. [DOI:10.1507/endocrj.E]14-0083]
32. Sahila M, Krisnapriya SL. Hypothyroidism, maternal obesity and self reported snoring as risk factors for pregnancy induced hypertension. J Med Sci Clin Res.2019; 7(8). [DOI:10.18535/jmscr/v7i8.149]

\section{How to Cite This Article:}

Mazloomi S, Alizadeh N, Shafiee G, Ghorbani S, Afsharirad M. The Effects of Hypothyroidism on Maternal Health. J Adv Med Biomed Res. 2021; 29 (136) :280-286

\section{Download citation:}

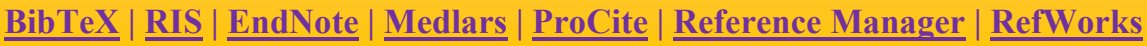

\section{Send citation to:}

(38. Mendeley 2 Zotero i) RefWorks RefWorks 